\title{
Coletivo TiVi Piraí: saúde mental e comunicação
}

\section{The TiVi Piraí collective: mental health and communication El colectivo TiVi Piraí: salud mental e comunicación}

\author{
Ilka de Araujo Soares ${ }^{1,2, a}$ \\ ilkaraujo@ymail.com | https://orcid.org/o0oo-0002-4216-827X \\ ${ }^{1}$ Prefeitura de Juiz de Fora. Juiz de Fora, MG, Brasil. \\ 2 Trabalharte Associação Pró Saúde Mental. Juiz de Fora, MG, Brasil. \\ a Mestrado em Comunicação e Cultura pela Universidade Federal do Rio de Janeiro.
}

\section{RESUMO}

O trabalho apresenta o Coletivo TiVi Piraí, um coletivo de comunicação e saúde mental ativo desde 2013, composto por usuários da Rede de Atenção Psicossocial de Juiz de Fora (MG). Trata-se do relato de uma experiência que se articula aos movimentos contemporâneos de grupalidades e que intenciona mudanças e melhorias nas políticas públicas no contexto da reforma psiquiátrica. Discorre sobre o percurso histórico de formação do grupo, contextualizado no processo de desinstitucionalização do município. O texto demonstra a importância do espaço de democratização da comunicação como recurso de estabelecimento de diálogo sociocultural e de reconstrução do imaginário estigmatizante e excludente acerca do portador de sofrimento mental. São apresentados aspectos de produção subjetiva na trajetória existencial dos integrantes da iniciativa, como também o acesso ao protagonismo, expressividade e exercício da cidadania.

Palavras-chave: Coletivo; Comunicação; Saúde Mental; Protagonismo; Subjetividade.

\begin{abstract}
The paper presents the Collective TiVi Piraí, a communication and mental health collective active since 2013 composed of Psychosocial Care Network of Juiz de Fora (MG) users. It frames the experience report linked to contemporary group movements that intend to change and improve public policies in the psychiatric reform context. It discusses the historical path of the group formation contextualized in the process of the municipality's deinstitutionalization. The text shows the importance of the communication space democratization as a resource for the establishment of socio-cultural dialogue and the reconstruction of the stigmatizing and excluding imaginary about the carrier of mental suffering. The aspects of subjective production are presented within the existential trajectory of the initiative members and the possibility of access to protagonism, expressiveness and citizenship exercise.
\end{abstract}

Keywords: Collective; Communication; Mental Health; Protagonism; Subjectivity. 


\section{RESUMEN}

El trabajo presenta el Colectivo 'TiVi Piraí', un colectivo de comunicación y salud mental activo desde 2013, compuesto por usuarios de la Red de Atención Psicosocial de Juiz de Fora (MG). Se trata del relato de una experiencia que se articula en los movimientos contemporáneos de grupos que intentan producir cambios y mejorías de las políticas públicas, en el contexto de la reforma psiquiátrica. Transcurre sobre el camino histórico de formación del grupo, contextualizado en el proceso de desinstitucionalización del municipio. El texto muestra la importancia del espacio democrático en la comunicación como un recurso para establecer el diálogo sociocultural y también de reconstrucción del imaginario que estigmatiza y excluye al portador de sufrimiento mental. Son presentados los aspectos más significativos de la producción subjetiva en la trayectoria existencial de los integrantes de la iniciativa, simultáneamente con la posibilidad de acceso al protagonismo, expresividad y ejercicio de la ciudadanía.

Palabras clave: Colectivo; Comunicación; Salud Mental; Protagonismo; Subjetividad.

Contribuição dos autores: a autora é responsável por todo o texto.

Declaração de conflito de interesses: não há.

Fontes de financiamento: não houve.

Considerações éticas: não há.

Agradecimentos/Contribuições adicionais: não há.

Histórico do artigo: submetido: 15 jun. 2021 | aceito: 1 jul. 2021 | publicado: 31 ago. 2021.

Apresentação anterior: não há.

Licença CC BY-NC atribuição não comercial. Com essa licença é permitido acessar, baixar (download), copiar, imprimir, compartilhar, reutilizar e distribuir os artigos, desde que para uso não comercial e com a citação da fonte, conferindo os devidos créditos de autoria e menção à Reciis. Nesses casos, nenhuma permissão é necessária por parte dos autores ou dos editores. 


\section{O COLETIVO TIVI PIRAÍ}

A iniciativa da Rádio/TiVi Piraí, a princípio consolidada no formato de oficina terapêutica, surgiu em agosto de 2013 no interior do centro de convivência da Rede de Atenção Psicossocial do município de Juiz de Fora (MG). Enquanto dispositivo comunicacional da modalidade web, a oficina de comunicação com produção destinada à circulação extrainstitucional é pioneira no campo da Saúde Mental nos referidos município e região. Sugestionados pelos movimentos mundiais de usuários em busca da autonomia e mobilizados pela importância de fortalecimento desta causa, os integrantes da saúde mental se reuniram com trabalhadores, voluntários e estagiários do serviço com a intenção de construir democraticamente um canal comunicacional.

A montagem inicial de uma oficina de rádio comunitária aproximou também acadêmicos dos cursos de comunicação, jornalismo, artes visuais e psicologia de universidades locais, de âmbito público e privado. Tal apoio prossegue até hoje, especialmente após a ampliação da perspectiva da rádio para a TV comunitária (que ocorreu em 2015) e, atualmente, para o Coletivo. A parceria com representantes (profissionais e estagiários) da área de comunicação e artes ocorre especialmente no que concerne à produção do material audiovisual da TiVi Piraí e a necessidade de apoio técnico para a gravação e edição dos programas. Acompanho o grupo desde sua criação, inicialmente na função de coordenadora do serviço mencionado, quando o formato estava circunscrito à oficina de comunicação e, atualmente, como voluntária do Coletivo TiVi Piraí, de comunicação e saúde mental, que se encontra em processo de ampliação dos espaços de produção e abrangência de seus membros, não mais circunscrito ao público de um serviço de saúde mental específico.

A idealização da oficina de comunicação comunitária foi paulatina, formada a partir da intenção do grupo de se reunir em torno da iniciativa de aquisição informacional, trabalho de elaboração de textos, produção de material de escrita, aprimoramento de leitura, debates sobre temas diversos e, principalmente, espaço de interação grupal e expressividade para consolidação de programas pautados, gravados ou filmados.

Boa parte dos membros da iniciativa teve a vivência de internação manicomial, mais ou menos duradora, alguns, inclusive, eram egressos recentes de confinamento e moradores de serviços residenciais terapêuticos, devido ao movimento de fechamento de hospitais psiquiátricos que o município atravessava. O lema da desinstitucionalização e da luta antimanicomial são bandeiras do grupo, o que abre espaço para verbalização da vivência do adoecimento mental, da exclusão social e da experiência da psiquiatrização hospitalar.

Ao nome inicialmente escolhido Radio Piraí, (que se estendeu, em seguida, para a perspectiva audiovisual, tornando-se TiVi Piraí), o grupo acrescentou o slogan 'Não desperdice a sua loucura!', em alusão ao convite ao diálogo social e à desconstrução do imaginário separatista entre loucura e uma suposta normalidade.

Desde o início, no momento do projeto da oficina de comunicação, foi preconizada a acessibilidade pública nas redes sociais (Facebook, Instagram e Youtube) para postagens dos programas. A partir da busca de apoio do jornalismo local, ocorreu a visibilidade de um programa especial da oficina de comunicação no jornal Tribuna de Minas e no 'Momento Cidadão' do site da Prefeitura de Juiz de Fora (houve publicação de programas sucessivos). Esse movimento do grupo, juntamente com seus apoiadores, ilustra o objetivo de interlocução social por meio dos veículos de comunicação. A consolidação do movimento de escoamento e visibilidade da produção também foi impulsionada pela visita da jornalista Daniela Arbex ao espaço de produção da oficina de comunicação, por ocasião da série de reportagens feitas para o jornal Tribuna de Minas, intitulada 'Histórias Roubadas', com segmento dedicado à Rádio Piraí, 'Histórias Reconstruídas', em novembro de 2014. 


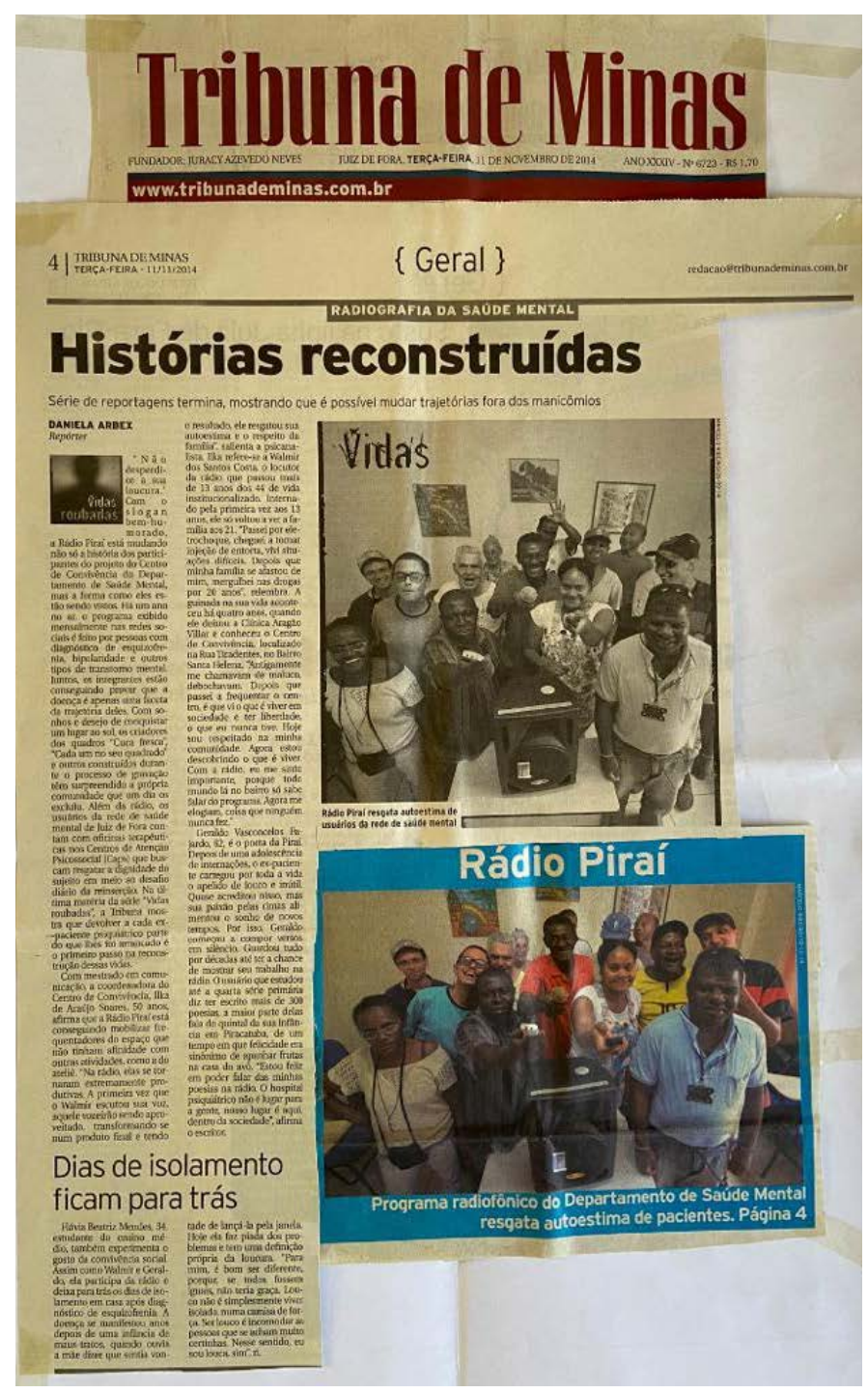

Figura 1 - Reportagem 'Histórias reconstruídas'

Fonte: Arbex, 2014.

A oficina foi concebida como experiência significativa no panorama da desospitalização psiquiátrica em Juiz de Fora ganhando apoio de profissionais da comunicação local com a proposta de iniciativas para a expansão e divulgação do trabalho produzido pelos usuários em meios de comunicação locais. A Rádio/ Tivi Piraí ultrapassou, a partir desses movimentos, o formato de 'oficina terapêutica', buscando enfatizar a circulação discursiva da produção de um grupo que porta a 'alteridade' como marca identitária proveniente da vivência do adoecimento mental, da exclusão social e da experiência da psiquiatrização hospitalar à qual muitos membros estiveram subjugados.

\section{PARA ALÉM DA OFICINA: PRODUÇÃO E PROGRAMAÇÃO}

Em sintonia com o processo de desinstitucionalização que o município de Juiz de Fora atravessa, a Rádio/TiVi Piraí tem evidenciado, desde a sua criação, a busca de proximidade e diálogo social. Na perspectiva de absorção das manifestações diferenciais e genuínas de seus integrantes, a TiVi Piraí tem sua programação estruturada em quadros específicos, cuja nomeação, composição e conteúdo passam pela escolha e posicionamento dos membros. Trata-se de uma questão importante a ser enfatizada porque toda a produção da programação é realizada grupalmente. A programação encontra-se articulada em quadros 
que são elaborados com a participação democrática dos integrantes nos encontros semanais e passam a fazer parte da grade de apresentações. Destacamos abaixo alguns quadros mais importantes já realizados:

- Quadro 'Antenados da Saúde Mental' - notícias sobre a Saúde Mental, composto de depoimentos dos próprios participantes, outros usuários da rede de atenção psicossocial, trabalhadores e autoridades; são realizadas visitas e entrevistas em diversas instâncias de saúde mental. Nesse quadro, os integrantes escolhem pautas, elaboram perguntas e se direcionam aos entrevistados;

- Quadro 'Loucatualidades' - notícias sobre atualidades, em que cabe o aspecto informacional a ser apreendido e propagado de temáticas importantes como direito, cidadania, meio ambiente, problemáticas sociais etc. É um espaço também de debate e entrevistas nas ruas, e comporta um bloco denominado 'Vozes da Rua';

- Quadro 'Cuca Fresca' - poesias pessoais ou de autores escolhidos, piadas, músicas e expressões próprias;

- Quadro 'Saradisso' - sobre saúde e qualidade de vida, inclui pesquisas e entrevistas com profissionais e a população em geral;

- Quadro 'Cada um no seu quadrado' - prioriza a manifestação de temas pessoais e a experiência de convivência familiar e social.

Esses quadros são trabalhados nos programas, incluindo também a grade musical escolhida grupalmente (RÁDIO E TIVI PIRAÍ, 2016a). É importante destacar que por envolver o grupo os gêneros musicais também são bastante diversos indo desde o sertanejo a músicas clássicas e óperas.

Outro quadro criado especialmente para a modalidade audiovisual é o 'Piraí em Alerta', que diz respeito ao posicionamento de sustentação por parte do grupo, das bases da luta antimanicomial, destacando a produção de textos de denúncia e alerta frente a atos políticos e administrativos que representem retrocesso na saúde mental, diante dos quais os integrantes se manifestam incisivamente contrários (RÁDIO E TIVI PIRAÍ, 2019b). Temos também o 'Louco vai rindo', quadro de humor no qual os participantes encenam piadas, pegadinhas etc. (RÁDIO E TIVI PIRAÍ, 2019c). Um destaque para este último é a intenção de fazer humor com experiências da loucura, do internamento psiquiátrico e de vivências do cotidiano, que, no dizer de alguns integrantes, representa a expressão da possibilidade de superação das marcas do estigma e do sofrimento mental: "Fazer humor com a loucura a partir do que já vivemos e que agora ficou no passado" (RÁDIO E TIVI PIRAÍ, 2016b, 2016c).

A partir dos trabalhos descritos e sua divulgação por colaboradores que compõem o grupo, assim como pelos integrantes da TiVi Piraí em encontros científicos, participação dos membros em mesas de debate (RÁDIO E TIVI PIRAÍ, 2018a; SOM ABERTO UFJF, 2017) e pela própria circulação dos programas nas redes sociais, o grupo foi se diversificando e solidificando o lugar protagonista de seus membros. A TiVi Piraí passou a receber funções importantes da Rede de Atenção Psicossocial (RAPS) com relação à elaboração de eventos locais, como o Dia Nacional da Luta Antimanicomial (18 de Maio) e o Dia Internacional da Saúde Mental (10 de Outubro).

A partir de 2016, todas as ações de protagonismo realizadas, até então, nas práticas grupais da oficina de comunicação passaram a ter função social mais relevante, pois, nos grandes eventos da saúde mental citados, ficou ao encargo do grupo apresentar temáticas representativas da Luta Antimanicomial e da garantia de direitos dos usuários da saúde mental.

Em 2016, no dia da luta antimanicomial, houve a apresentação de uma encenação intitulada Saradisso, na Escola de Governo do município, para autoridades locais, instâncias gestoras, trabalhadores e usuários dos serviços, familiares e comunidade. Consistia na apresentação de um texto satírico sobre a 'morte dos 
hospitais psiquiátricos', (designação que o grupo concedeu à temática da apresentação), tendo em vista o processo de desospitalização transcorrido no município e que retratava a nomeação destes espaços que foram, outrora, locais de passagem ou permanência continuada de vários integrantes presentes na dramatização.

Em 2017, também por ocasião das comemorações do 18 de maio, a encenação Superar é Genial! reuniu texto informativo, roteiro musical e produção plástica, em uma apresentação em praça pública e em anfiteatros de universidades locais. Os figurinos da apresentação foram elaborados por artistas locais parceiros que produziram, a partir das diretrizes trabalhadas pelo grupo da TiVi Piraí, uma rica indumentária, representativa de personagens históricos os quais portaram marcas diferenciais e graves impedimentos ou limitações em sua trajetória de vida e que tiveram o aspecto da 'superação' representado pela criação e a inventividade no campo das artes ou da literatura.

Os integrantes da TiVi Piraí se dividiram: enquanto uns apresentaram o texto explicativo sobre os personagens, outros encenaram o desfile portando as indumentárias dos referidos personagens (Bispo do Rosário, Profeta Gentileza, Van Gogh, Frida Kahlo, Beethoven, Aleijadinho, Pollock etc.). Após a apresentação pública em um parque central da cidade, houve convite para repetição do espetáculo em outro evento cultural de grande porte na Universidade Federal (UFJF). O grupo realizou uma produção musical (rap) acerca desses personagens encenados e inspiradores. Essas realizações culminam em produção de vídeos que são divulgados e impulsionados nas redes sociais. Os integrantes narram a grande satisfação pelo reconhecimento de um trabalho desenvolvido e que se aprimora a cada nova tarefa, dando indicadores de um significativo acesso à cidadania e reconstrução do lugar social dos participantes (RÁDIO E TIVI PIRAÍ, 2017).

Em 2018, também no dia 18 de maio, a temática desenvolvida pelo grupo na encenação pública foi 'Descaminhos da Loucura: da exclusão à dignidade'. Tratou de um levantamento histórico - no formato de uma 'ópera de rua' - da Antiguidade à Contemporaneidade, sobre a trajetória do personagem da loucura. A apropriação do grupo de conhecimentos sobre tema, treino de leitura e dramatização nos distintos segmentos da apresentação renderam importante repercussão social e mais um valioso acréscimo na experiência de interação grupal (RÁDIO E TIVI PIRAÍ, 2018b, 2019a, APRESENTAÇÃO..., 2018).

No ano de 2019, na peça Histórias de vida e de luta, o grupo decidiu por uma apresentação com narrativas de histórias pessoais sobre o sofrimento mental de alguns integrantes. Propuseram descrever seu percurso, a fim de ser encenado pelos membros que se colocaram disponíveis (RÁDIO E TIVI PIRAÍ, 2019d). Todo este resgate histórico se faz necessário uma vez que se pretende consolidar a importância do processo comunicacional como mobilizador e potencializador da grupalidade e consequentemente da subjetividade. A participação cidadã certamente se consolidou desde as reuniões de pauta para a seleção das temáticas candentes a serem abordadas.

Atualmente, a TiVi Piraí tem se consolidado como um 'Coletivo de Comunicação e Saúde Mental' e segue não mais atada a um serviço de saúde mental específico e sim implementando parcerias com espaços socioculturais diferenciados. O exercício comunicacional no âmbito do coletivo tem se constituído enquanto meio alternativo que opera como forma de legitimação de existências alteras em busca de espaço de expressão e inserção social. A seguir, serão apresentadas as bases de fundamentação desta prática, contextualizadas no processo de desinstitucionalização psiquiátrica.

Como movimento múltiplo que pretende alcançar, estrategicamente, todos os espaços envolvidos e condicionados ao modelo tradicional instituído - o modelo manicomial - com o qual se intenciona romper, a desinstitucionalização objetiva reconstruir conceitos e representações, assim como redefinir o espaço simbólico da loucura nas instituições e na sociedade (PASCIUTTI, 1997). Tal propósito é vislumbrado em cada encontro e em cada nova produção que o Coletivo tem se empenhado a realizar. 


\section{PRODUÇÃO SUBJETIVA E COMUNICAÇÃO}

Os estudos de Goffman (1974) sobre a vivência da hospitalização psiquiátrica advogam sobre a ocorrência de uma experiência de expropriação das relações sociais neste processo, marcado por isolamento e estigmatização. A dissociação do meio externo e a imersão no mundo hospitalar incapacitam a retomada dos contatos na vida, induzindo, inclusive, ao reforço de quadro patológico (patoplastia). O isolamento social produzido pela experiência do asilamento culmina na intensificação da impossibilidade de o indivíduo criar vínculo com a sua experiência subjetiva, levando-o à alienação de suas ações imediatas e à diminuição ou perda de sua capacidade cognitiva e crítica, especialmente com relação aos dispositivos de tratamento aos quais está subjugado.

Conforme aponta Michel Foucault (1975), no processo de institucionalização da loucura, além da necessidade de abolição do espaço social do seu protagonista, em função do crescimento das cidades e da industrialização, ocorre, também, com a psiquiatrização da doença mental, a redução da loucura ao saber médico e ao seu domínio prático. O estatuto de objeto desse saber desbasta da loucura sua 'verdade' e a possibilidade de apresentar-se para além da instância perpétua do julgamento. Descreve Foucault: "O louco tinha que ser vigiado nos seus gestos, rebaixado nas suas pretensões, contradito no seu delírio, ridicularizado nos seus erros..." (1975, p. 83). O louco, minorizado, encontra-se incontestavelmente aparentado com a criança, e a loucura, culpabilizada, acha-se originalmente ligada ao erro.

No contexto da Reforma Psiquiátrica, as ações substitutivas do modelo asilar, calcadas nas Políticas Públicas de Saúde Mental, configuram-se como propostas de inserção/participação social transformadoras do posicionamento social dos portadores de sofrimento mental, concebidos enquanto minorias em situação de desvantagem social. A desinstitucionalização preconizada como objetivo máximo das ações no campo da saúde mental é reconhecida como um movimento extenso e complexo que, ao oferecer novas formas de cuidado - emergentes da sustentação do lema de promoção da vida - constrói inovadas modalidades de sociabilidade e subjetividade. Conforme afirma Rotelli (1990), a reconstrução pretendida:

Tende a mobilizar os sujeitos sociais envolvidos... tende a transformar as relações de poder entre os pacientes e as instituições... tende a produzir estruturas de saúde mental que substituam inteiramente a internação no hospital psiquiátrico e que nascem da desmontagem e reconversão dos recursos materiais e humanos que estavam ali depositados. (ROTELLI, 1990, p. 18)

É preciso reforçar que sobre o panorama específico do surgimento do Coletivo, o município de Juiz de Fora experimenta um processo de desinstitucionalização gradativo, por meio do qual têm sido elaboradas ações para implementação do modelo substitutivo às práticas de internamento, representado pela construção de uma rede de cuidados alternativa. O fechamento de todos os hospitais psiquiátricos da cidade - que foi polo importante de internações psiquiátricas no passado - é um fato que data de 2014, e tem contado com a implementação dos serviços Residenciais Terapêuticos (casas onde residem pacientes antes internados e com histórico de abandono social e familiar) e da Rede de CAPS (Centro de Atenção Psicossocial, incluindo funcionamento 24 horas). Dentre as iniciativas de reabilitação psicossocial, situamse os centros de convivência e cultura e as associações de usuários, suportes com os quais a oficina de comunicação iniciou suas atividades. A proposta central dessas instâncias se refere à constituição de um ambiente voltado para práticas de interação social e para o exercício da autonomia por meio de oficinas diversas, práticas culturais e de geração de trabalho e renda.

A longa trajetória de exclusão social, condicionada principalmente às práticas de confinamento manicomial, problematiza, na memória histórica civilizacional, o lugar desses indivíduos. É função da RAPS 
projetar e elaborar ações múltiplas concernentes aos variados campos de atuação que incidam enquanto tentativas de reversão deste quadro.

A Rádio/TiVi Piraí tem na sua composição membros que, diante do processo de desinstitucionalização municipal descrito, contaram com o apoio dos serviços substitutivos e foram incluídos nas práticas de reabilitação psicossocial, dentre elas o dispositivo comunicacional aqui apresentado. São frequentes os depoimentos dos integrantes sobre a experiência de psiquiatrização, a elaboração de programas temáticos de denúncia contra retrocessos nas políticas públicas, especialmente na esfera federal, assim como críticas e posicionamentos quanto ao quadro da saúde pública municipal.

A experiência de produção de narrativas pessoais nos programas - tanto quanto o estímulo dos participantes do Coletivo, direcionado a outras pessoas em tratamento em alguma instância da RAPS - é algo que notoriamente produz naqueles que são 'convidados' (a dar entrevista ou integrar os programas de alguma forma) efeitos importantes. Vários membros do Coletivo se sentem motivados a ir ao encontro aos usuários que se apresentam em condição desfavorável e fragilizados para incentivá-los a se expor e se integrar. É gerado um clima de amistosidade interessante e que pode impulsionar o engajamento dos sujeitos envolvidos. Tivemos essa experiência durante a realização de entrevistas para um programa sobre residências terapêuticas (RTs), nas quais os integrantes entrevistaram ex-pacientes psiquiátricos, seus contemporâneos de vivências passadas em internações psiquiátricas, após o que, alguns destes tiveram interesse em participar de eventos junto ao Coletivo.

Concomitantemente à aquisição de maior autonomia e exercício da cidadania com as experiências de participação e integração social, as práticas comunicacionais desenvolvidas pelo Coletivo têm recolhido ganhos significativos quanto ao aspecto subjetivo, particular, de alguns membros participantes, conforme será exposto a seguir.

A experiência da Rádio e TiVi Piraí tem indicado a possibilidade de contorno e apaziguamento de algumas vivências impulsivas, errantes e fragmentárias, que, com frequência, povoam a experiência de sofrimento mental apresentada por vários integrantes com a inserção destes na proposta de reabilitação em questão. Os membros do Coletivo Rádio e TiVi Piraí ingressam na iniciativa por portarem quadros mentais persistentes como neuroses graves e psicoses e/ou por estarem distanciados do convívio social, devido ao acometimento psíquico. Alguns evidenciam manifestações que, em geral, são concebidas como contraproducentes para as perspectivas de trabalho cognitivo. Em momentos mais críticos, apresentam manifestações de distorção da realidade, comprometimento da atenção, da linguagem e do juízo crítico, assim como expressões de dispersão, empobrecimento ideativo, da afetividade e negativismo quanto às iniciativas de trabalho.

É possível refletir brevemente sobre a particularidade simbólica nesses quadros, marcada pelo prejuízo da partilha de códigos sociais e comprometimento da localização na ordem simbólica (LACAN, 1998). O processo de estabilização psíquica, observado em usuários integrantes da oficina de comunicação que utilizam a reprodução televisiva, por meio do recurso audiovisual -, pode ser pensado no sentido do 'suprimento' de elementos em relação aos quais, estruturalmente, esses sujeitos encontram-se desfavorecidos. O recurso televisivo e a execução de funções específicas (ver-se projetado, aperfeiçoar a forma de exposição, elaborar textos, entrevistar, filmar etc.) pode se constituir como possibilidade de dar consistência à imagem corporal, minimizando o percalço e o abalo de uma potência simbólica ordenadora (GUERRA, 2007), ao mesmo tempo que reconstrói a alternativa de prover uma pluralidade de soluções possíveis, podendo, então, conferir uma ancoragem subjetiva. A aquisição de uma nomeação por meio do exercício de papéis no Coletivo insinua a possibilidade de criação do laço social, até então inacessível para alguns sujeitos. É assim que assistimos participantes que passaram a realizar composições musicais próprias (para além do que o próprio grupo produz) as quais tiveram o destino de produção de vídeo 
individual, como também outros integrantes que passaram a ter acesso amplo ao recurso da leitura e à locução nos programas e eventos, após longos anos de fracasso escolar e insucesso quanto a essa aquisição.

As relações de pertencimento ao grupo e o trabalho psíquico centrado no dispositivo da linguagem parecem, pois, operar sobre o sentimento de 'deriva', tão comum nestes sujeitos, abrindo a possibilidade de migrar desse lugar, ao encontro de um solo mais seguro, referenciado pelo alicerce simbólico que o grupo pode oferecer.

Ao pensar as relações no campo institucional, Guattari (1992) afirma que o mundo altero com o qual a psicose entra em diálogo não é unicamente de ordem imaginária, delirante e fantasmática... encarna-se igualmente no meio social e material do cotidiano. Dessa forma, a fomentação de mudanças no campo intrasubjetivo e no contexto pragmático (GUATTARI,1992), criadas com base no viés comunitário, pode gerar condições favoráveis para transformações significativas na particularidade comunicacional em questão.

No contato com as produções da Rádio e TiVi Piraí nestes 7 anos de existência, tem sido possível observar que elementos do funcionamento das oficinas - tal como o aprimoramento da linguagem (por meio de leituras e produções de textos e do exercício das funções de locução, repórter, entrevistador etc.), a apropriação da própria imagem (por meio da escuta e percepção da voz e da autoimagem), o sentido de participação, utilidade e produtividade (na execução dos programas, no contato com o produto final e sua repercussão nas redes sociais, na família e no bairro) - incidem de modo relevante, demonstrando causar interesse, prazer e envolvimento dos integrantes. Esses aspectos, em geral, retratam uma condição subjetiva diferenciada daquela inerente ao quadro sintomatológico apresentado por vários integrantes quando da sua inserção no serviço de saúde mental. As reuniões e a expectativa de atuar nos programas se apresentam com uma frequência representativa do interesse que desperta nos usuários.

O efeito de envolvimento e vinculação dos participantes no trabalho - cuja ênfase se dá na palavra norteia a própria história, remete às considerações de que o sujeito, desde a origem, está ligado ao outro pela via da palavra, meio legítimo de intercâmbio (RIBEIRO, 2003). É a palavra que presentifica a cultura e a pólis. É esse sujeito, desde sempre político, que os dispositivos comunicacionais na saúde mental podem fazer emergir.

Observa-se, assim, que a criação de um campo de relações pragmaticamente calcado nas ferramentas da comunicação e no pertencimento grupal tem efeitos subjetivos e representa uma possibilidade de reposicionamento do portador de sofrimento mental com a capacidade produtiva - processo que pode se dar concomitantemente ao exercício da cidadania e acesso à posição de protagonismo na expressão da causa da saúde mental, aspectos que serão expostos a seguir.

A tendência crescente de interconexão entre diferentes partes do mundo, por meio da extensiva proliferação dos canais de comunicação e da difusão de informação, tem trazido complexidade às formas de interação social. O caráter desigual da comunicação globalizada é evidenciado mediante o desenvolvimento de conglomerados de comunicação, que, conforme aponta Thompson (1998), "promovem a formação de grandes concentrações de poder econômico e simbólico que são privadamente controlados e desigualmente distribuídos, e que dispõem de recursos maciços para garantir os objetivos corporativos da arena global" (p.144).

Por outro lado, Peruzzo (1998) assinala que a democratização da comunicação, a apropriação dos meios massivos para a comunicação das minorias, a invenção de novos sentidos e dispositivos de expressão singulares podem ser alternativas de operar frente à massificação estética e ideológica de padronização e homogeneização das sociedades, solidificada pela grande mídia.

Em outro estudo (SOARES, 2004), considerei relevantes as pontuações de Canclini (1999) ao enfocar a utilização de um meio de comunicação de expressão prioritariamente Global na esfera do Local, tal como 
ocorre nas iniciativas de comunicação comunitária. O autor delineia que o que parece estar em questão são as oportunidades, aí geradas, de convivência com a heterogeneidade, a diferença e a desigualdade. Destaca que o surgimento de espaços inovados de intermediação cultural e sociopolítica, enquanto instituições mais flexíveis, pode se constituir em vias de proliferação de redes dedicadas à "negociação da diversidade" (CANCLINI, 1999, p. 31).

Face ao predomínio de um gigantesco processo de simulação nos meios televisivos hegemônicos, que tendem a extrair as possibilidades de produção de sentido, e diante dos quais apenas é possível posicionarse pelo fascínio e pela imersão na imaginação, os veículos comunicacionais comunitários investem em uma proposta alternativa. Embora não abrindo mão do desenvolvimento tecnológico (estando, portanto, condicionados aos mecanismos prevalecentes nesse campo), utilizando um meio compatível com o processo global, essas iniciativas diferenciam-se, entretanto, do que se supõe ser o poder isolado e esvaziado de sentido engendrado naquele.

Isso ocorre em razão dessas iniciativas se referenciarem na união de pessoas com objetivos partilhados, cujas práticas são balizadas na inscrição de um determinado pertencimento territorial, na importância do poder decisório entre os membros e na tentativa de retratação de seu real-histórico pelo meio comunicacional escolhido (PAIVA, 1998). Referendadas pela especificidade de grupos determinados, as iniciativas dos meios de comunicação comunitária se consolidam pela possibilidade de promover a conscientização sobre suas causas, reivindicação de cidadania e mudança de sua realidade.

É da constatação de que as diferenças e conflitos não se reduzem ao encontro de uma identidade homogênea que se pronuncia a compreensão do desenvolvimento das mídias alternativas, dos meios de comunicação de uso comunitário. Estes visam o reconhecimento de identidades sociais múltiplas, cuja ótica versa exatamente pelo seu uso como forma de legitimação de comportamentos e existências que se baseiam em patamares diferenciados daqueles predominantemente evocados no uso corrente dos meios de comunicação.

Assim, face à velocidade do mundo contemporâneo e ao excesso informacional, o uso dos meios de comunicação - quando de base comunitária - representam importantes dispositivos de ação, caracterizados por ênfase na partilha dos códigos sociais, concessão de sentido às ações executadas e a possibilidade de reconstrução identitária. A TiVi Piraí, nesse sentido, tem trabalhado rumo à reconfiguração da imagem da loucura, utilizando meios globais (linguagem televisiva) e recrutando a participação simultânea dos membros (sujeitos, em geral, apartados de qualquer participação social) em todo o processo, mediante uma organização interna embasada nas relações de participação comunitária (local).

Nas práticas comunitárias de comunicação, sob inspiração das prerrogativas do campo da Saúde Mental de incentivo à autonomia e inclusão social, é de grande relevância o uso do potencial da linguagem, como alternativa de abarcar a particularidade dos sujeitos aí envolvidos, atribuindo a estes a possibilidade de se posicionarem, de modo próprio, enquanto sujeitos ativos na reelaboração do sofrimento e na reinvenção da vida. A versão comunitária da Rádio/TiVi Piraí transforma os usos, gêneros e linguagens radiofônicos e audiovisuais de acordo com os objetivos particulares do grupo. As práticas comunicacionais no campo da Saúde Mental, nesse sentido, podem atuar como um campo pragmático, que instiga novas formas de subjetivação e defesa da alteridade, a partir das relações de pertencimento e do fortalecimento da experiência singular da loucura.

\section{CONSIDERAÇÕES FINAIS}

O dispositivo comunicacional, no contexto da desinstitucionalização, se constitui como uma importante ferramenta de negociação do lugar social do portador de sofrimento mental. A utilização de mídias alternativas (rádio e TV comunitárias) como formas de comunicação desta minoria e a invenção de novos 
sentidos e dispositivos de expressão singular podem representar uma via diferenciada de operar frente à massificação estética e ideológica de padronização, homogeneização e segregação na sociedade.

O surgimento de identidades culturais múltiplas e a criação de novos movimentos no interior do espaço cultural na contemporaneidade suscitam um processo amplo de mudanças que desloca as estruturas das sociedades e abala os quadros de referência que davam aos indivíduos uma ancoragem estável no mundo social. Por outro lado, isso pode permitir a absorção de expressões originais e múltiplas e a incorporação de modelos informais e distanciados de uma lógica linear e universalizante.

No âmbito da comunicação comunitária, os programas, eventos e apresentações públicas do Coletivo TiVi Piraí ressaltam as perspectivas de exercício de protagonismo, cidadania e garantia de direitos que incrementam as pautas da luta antimanicomial. Destacam-se não só as manifestações diferenciais, criativas e espontâneas, o humor inventivo, mas também as narrativas pessoais, calcadas no histórico de exclusão social e da psiquiatrização.

Enquanto 'coletivo' - formato atual do grupo de comunicação e saúde mental - há projeção de contatos com outros grupos em situação de desvantagem social, frentes de economia solidária, ambientes de produção cultural etc., iniciativa que agrega e concretiza a solidificação do fortalecimento da voz e do lugar de minorias em evidência no cenário contemporâneo.

Mediante as experiências promissoras do Coletivo Rádio/TiVi Piraí, urge que esses espaços prossigam como propulsores de ultrapassagem da concepção da loucura - em sua face condicionada e confinada à marginalidade segregada -, na perspectiva de que as ações grupais se direcionem rumo à criação de vias legítimas de sustentação das subjetividades, negociação da diversidade e reconstrução da dívida histórica circunscrita no imaginário social sobre o sofrimento mental.

\section{REFERÊNCIAS}

APRESENTAÇÃO DA ÓPERA DE RUA: (DES)Caminhos da loucura da Exclusão à Dignidade. Juiz de Fora: [s. n.], 31 de maio 2018. 1 vídeo (32:54 min). Publicado pelo canal Tivi Piraí. Disponível em: https://www. youtube.com/watch?v=uB52BG4k-x0\&ab_channel=TiviPira\%C3\%AD. Acesso em: 4 jun. 2020.

ARBEX, Daniela. Histórias reconstruídas. Tribuna de Minas. Juiz de Fora, MG, 11 nov. 2014. Cidade. Disponível em: https://tribunademinas.com.br/noticias/cidade/11-11-2014/historias-reconstruidas.html. Acesso em: 25 ago. 2020.

CANCLINI, Nestor García. La globalización imaginada. Barcelona: Paidós, 1999.

FOUCAULT, Michel. Doença mental e psicologia. Rio de Janeiro: Tempo Brasileiro, 1975.

GUATTARI, Félix. Caosmose: um novo paradigma estético. Rio de Janeiro: Editora 34, 1992.

GOFFMAN, Erving. Manicômios, prisões e conventos. São Paulo: Perspectiva, 1974.

GUERRA, Andrea Maris Campos. A estabilização psicótica na perspectiva borromeana: criação e suplência. 2007. 270 f. Tese (Doutorado em Teoria Psicanalítica) - Universidade Federal do Rio de Janeiro, Rio de Janeiro, 2007.

LACAN, Jacques. O estádio do espelho como formador da função do Eu. In: LACAN, Jacques. Escritos. Trad. Vera Ribeiro. Rio de Janeiro: Zahar, 1998. p. 96-105.

PASCIUTTI, Jacyara Carrijo Rochadel. Pensando a Desinstitucionalização: alguns aspectos institucionais e das representações sociais. Cadernos do IPUB, Rio de Janeiro, v. 7, p. 96-120, 1997.

PERUZZO, Cicilia M. Krohling. A comunicação nos movimentos populares: a participação na construção da cidadania. Petrópolis: Vozes, 1998.

PAIVA, Raquel. O Espírito Comum: comunidade, mídia e globalismo. Petrópolis: Vozes, 1998. 
RÁDIO E TIVI PIRAÍ. $1^{\circ}$ bloco 18 de maio de 2019 - "Descaminhos na viagem que tivemos". Juiz de Fora, 07 de ago. 2019a. Facebook: radioetivipirai. Disponível em: https://www.facebook.com/ watch/?v=1177584182430894. Acesso em: 20 jun. 2020.

RÁDIO E TIVI PIRAÍ. Alerta! Piraí em alerta. Juiz de Fora, 06 jun. 2019b. Facebook: radioetivipirai. Disponível em: https://www.facebook.com/watch/?v=2283579398561920. Acesso em: 15 ago. 2020.

RÁDIO E TIVI PIRAÍ. Alô queridos internautas que se ligam na TiVi Piraí. Juiz de Fora, 7 dez. $2016 a$. Facebook: radioetivipirai. Disponível em: https://m.facebook.com/story.php?story fbid=711794095637013\& $\underline{\mathrm{id}=403279029821856}$. Acesso em: 5 jul. 2020.

RÁDIO E TIVI PIRAÍ. Aniversário de três anos da Rádio e TiVi Piraí. Juiz de Fora, 2 de nov. $2016 \mathrm{~b}$. Facebook: radioetivipirai. Disponível em: https://www.facebook.com/watch/?v=692126047603818. Acesso em: 30 ago. 2020.

RÁDIO E TIVI PIRAÍ. Comunitarismo e Subjetividade no campo da Saúde Mental. Juiz de Fora, 27 de out. 2018a. Facebook: radioetivipirai. Disponível em: https://www.facebook.com/radioetivipirai/photos/a.108737428 8078990/1119227984893620/?type=3\&theater. Acesso em: 7 jul. 2020.

RÁDIO E TIVI PIRAÍ. Especial de Natal. Juiz de Fora, 21 dez. 2016c. Facebook: radioetivipirai. Disponível em: https://www.facebook.com/watch/?v=719245071558582. Acesso em: 20 ago. 2020.

RÁDIO E TIVI PIRAÍ. Louco vai rindo. Juiz de Fora, 12 jun. 2019c. Facebook: radioetivipirai. Disponível em: https://www.facebook.com/watch/?v=355338341700643. Acesso em: 7 jun. 2020.

RÁDIO E TIVI PIRAÍ. No dia da luta antimanicomial. Juiz de Fora, 07 de ago. 2019d. Facebook: radioetivipirai. Disponível em: https://www.facebook.com/radioetivipirai/posts/1320828728066877. Acesso em: 15 jun. 2020.

RÁDIO E TIVI PIRAÍ. RAP (Des)caminhos da Loucura: Da exclusão à Dignidade. Juiz de Fora, 4 de out. 2018b. Facebook: radioetivipirai. Disponível em: https://www.facebook.com/watch/?v=2195282637411535. Acesso em: 15 jun. 2020.

RÁDIO E TIVI PIRAÍ. Superar é genial. Juiz de Fora, 30 de nov. 2017. Facebook: radioetivipirai. Disponível em: https://www.facebook.com/watch/?v=895909210558833. Acesso em: 20 ago. 2020.

RIBEIRO, Maria Anita Carneiro. A neurose obsessiva. Rio de Janeiro: Jorge Zahar Editora, 2003.

ROTELLI, Franco. Desinstitucionalização. São Paulo: Hucitec, 1990.

SOARES, Ilka de Araújo. Comunicação e saúde mental: a democratização dos meios comunicacionais como veículo de reconstrução identitária. Psicologia Ciência e Profissão, Brasília, DF, v.24, n.4, p.12-21, 2004. DOI: http://dx.doi.org/10.1590/S1414-98932004000400003. Disponível em: https://www.scielo.br/scielo. php?script=sci arttext\&pid=S1414-98932004000400003\&Ing=pt\&tlng=pt. Acesso em: 5 jul. 2020.

SOM ABERTO UFJF. Som aberto edição de Natal. Juiz de Fora, 16 dez. 2017. Facebook: somabertoufjf. Disponível em: https://www.facebook.com/somabertoufjf/photos/?tab=album\&album_id=1494462120860505\& tn $=-U C-R$. Acesso em: 5 jul. 2020.

THOMPSON, John Brookshire. A mídia e a modernidade: uma teoria social da mídia. Petrópolis: Vozes, 1998. 